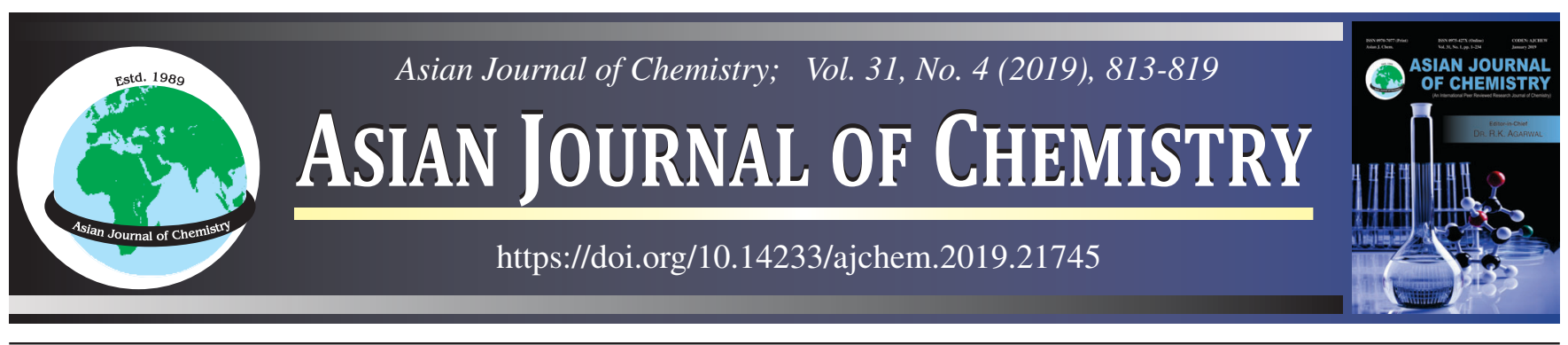

\title{
Synthesis, Characterization, Photocatalytic Activities and Reusability of Eu-ZnO-Ag Nanoparticles using Sunlight/LEDs Illuminations
}

\author{
Y. Jerlin Jose ${ }^{1}$, S. Joseph Selvaraj $^{1}$ and M. Manjunathan ${ }^{2, *}, \bullet$
}

${ }^{1}$ Department of Chemistry St. Joseph's College, Tiruchirappalli-620002, India

${ }^{2}$ Department of Chemistry, BWDA Arts and Science College, Villupuram-604304, India

*Corresponding author: E-mail: manjunath876@gmail.com

Received: 6 October 2018;

Accepted: 7 January 2019;

Published online: 27 February 2019;

AJC-19290

\begin{abstract}
Photocatalyst (Eu-ZnO-Ag) was synthesized by precipitation-decomposition process. The characterization catalyst by phase and size of catalyst by powder-XRD, morphology of catalyst by FE-SEM and optical properties by UV-visible and emission spectroscopy. The photocatalytic action of $\mathrm{Eu}-\mathrm{ZnO}-\mathrm{Ag}$ was investigated in the photodegradation of methylene blue dye in water under LEDs/solar light $\mathrm{Eu}-\mathrm{ZnO}-\mathrm{Ag}$ catalyst is indicating the excellent activity than $\mathrm{Ag}-\mathrm{ZnO}, \mathrm{Eu}-\mathrm{ZnO}$ commercial $\mathrm{ZnO} / \mathrm{TiO}{ }_{2}$ nanoparticles. Co-dopants (Eu/Ag) shift the light absorbance of $\mathrm{ZnO}$ toward visible region. Factor affecting of photodegrdation study by dose, dye, solution $\mathrm{pH}$ on of methylene blue dye present solar/LEDs. The Eu-ZnO-Ag is established to be reusable photocatalyst. A potential photodegradation of methylene blue mechanism was discussed under illuminations LEDs/solar light.
\end{abstract}

Keywords: Nanoparticles, Sunlight, LEDs, Photodegradation of methylene blue dye.

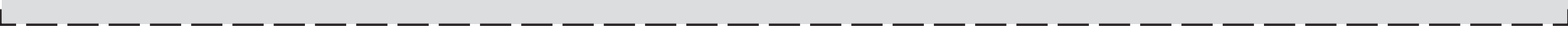

\section{INTRODUCTION}

Photocatalysis is shown excellent activity for solving many current issues, Industries waste water such as textiles, pharmaceuticals, plastics, rubber, printing, etc., May transport great terrorization to the water environment, due to the waste water pollutants and harmful chemicals affected the environmental area and liveliness issues. These types of pollutants are challenge and useful research in the environmental science. Semiconductor and metal doped-semiconductor recommend the potential for exclusion of toxic chemicals through their adsorption and photochemical methods are wide applicability [1-3]. Heterogeneous photo-catalysis with metal doped-metaloxides are widely investigation of degradation of air and waste water, but also for alternative energy materials. Photocatalysts of pure/doped $\mathrm{TiO}_{2}, \mathrm{ZnO}$ and metal doped metal-oxides are applied to a diversity of environmental processes such as remediation of harmful chemicals and water pollutants [4-8].

The depend of metals, such as $\mathrm{Cu}$ [9], $\mathrm{Ag}$ [10] and $\mathrm{Au}$ [11] on semiconductor oxides are reported to increase their catalytic activity Recently, concurrent doping of two kinds of ions into metal-oxides materials has involved considerable interest, as it could result in a higher photocatalytic activity and performance compared with mono metal ion doping into semiconductors, such as $\mathrm{Ag}^{+}$and lanthanide-doped $\mathrm{ZnO}$ [12] observed good performance for its exclusive $4 f$ electron configuration of lanthanides. Eu-doped $\mathrm{ZnO}$ have attracted interest due to the $\mathrm{Eu}^{3+} / \mathrm{Eu}^{2+}$ redox couple $[13,14]$ Many studies have shown that $\mathrm{La}$ doping enhances the photocatalytic activity of $\mathrm{ZnO} /$ $\mathrm{TiO}_{2}$ [15-17]. The reported synthesized Sm-ZnO-Ag through precipitation decomposition method, which showed highly excellent photocatalytic activity in thiazin type (methylene blue) degradation [18]. The catalytic performances of the Eu$\mathrm{ZnO}-\mathrm{Ag}$ catalysts were investigated in water, catalytic activation for methylene blue degradation, outstandingly performance of Eu-ZnO-Ag was found to have excellent activity and excellent stability in co-catalytic activation of europium/silver for methylene blue dye degradation present of LEDs/solar light illuminations.

\section{EXPERIMENTAL}

The methylene blue dye (99\%) and $\mathrm{Zn}\left(\mathrm{NO}_{3}\right)_{2} \cdot 6 \mathrm{H}_{2} \mathrm{O}(\mathrm{AR})$, $\mathrm{AgNO}_{3}$ and $\mathrm{Eu}\left(\mathrm{NO}_{3}\right)_{3} \cdot 6 \mathrm{H}_{2} \mathrm{O}$ were purchased from SigmaAldrich and Merck. All the chemical reagents purchased and

This is an open access journal, and articles are distributed under the terms of the Creative Commons Attribution-NonCommercial-ShareAlike 4.0 (CC BY-NC-SA 4.0) International License which allows readers to freely read, download, copy, distribute, print, search, or link to the full texts of its articles and to use them for any other lawful non-commercial purpose as long as the original source is duly acknowledged. 
used for AR grade without further purifications. All the experiment using triple distilled water is taken to prepare (alkaline $\mathrm{KMnO}_{4}$ ) experimental solutions. The maintained $\mathrm{pH}$ of solution by addition of acid or base before doing irradiation experiment.

Preparation of Eu-ZnO-Ag nanoparticles: A precipitation decomposition method is applied to prepare $\mathrm{Eu}-\mathrm{ZnO}-$ Ag catalyst (Scheme-I). A $100 \mathrm{~mL}$ of zinc nitrate hexahydrate $(0.8 \mathrm{M})$ and $100 \mathrm{~mL}$ of oxalic acid $(1.2 \mathrm{M})$ in triple distilled water used to homogenous was boiled separately. Both are 5 $\mathrm{mL}$ of $\mathrm{AgNO}_{3}(2 \% \mathrm{Ag})$ solution and $5 \mathrm{~mL}$ of $\mathrm{Eu}\left(\mathrm{NO}_{3}\right)_{3}(8 \%$ $\mathrm{Eu})$ solution added slowly one by one with constant stirring of zinc nitrate bulk solution were heated for $1 \mathrm{~h}$ at $60-70{ }^{\circ} \mathrm{C}$. Further adding of oxalic acid into bulk solution. The mixture of $\left[\mathrm{Eu}\left(\mathrm{NO}_{3}\right)_{3}+\mathrm{AgNO}_{3}+\mathrm{Zn}\left(\mathrm{NO}_{3}\right)_{2}\right]$ oxalic acid solution was formed. Finally precipitation of Eu-zinc-Ag oxalate occurred when the solution was cooled to room temperature. The Euzinc-Ag oxalate powder washed with triple distilled water and dried at $100{ }^{\circ} \mathrm{C}$ for $6 \mathrm{~h}$. The Eu-Zinc-Ag oxalate powers were calcinated at $10{ }^{\circ} \mathrm{C}$ per mints in a muffle furnace reach the decomposition $\left(450^{\circ} \mathrm{C}\right)$ temperature. The $\mathrm{Eu}-\mathrm{ZnO}-\mathrm{Ag}$ catalyst was collected and used for further analysis. This catalyst contained $8 \mathrm{wt} \%$ of Eu. Other catalyst are prepared by same procedure with or without $(\mathrm{Ag} / \mathrm{Eu})$ and percentage of metal ions with appropriate amounts of the respective precursors.

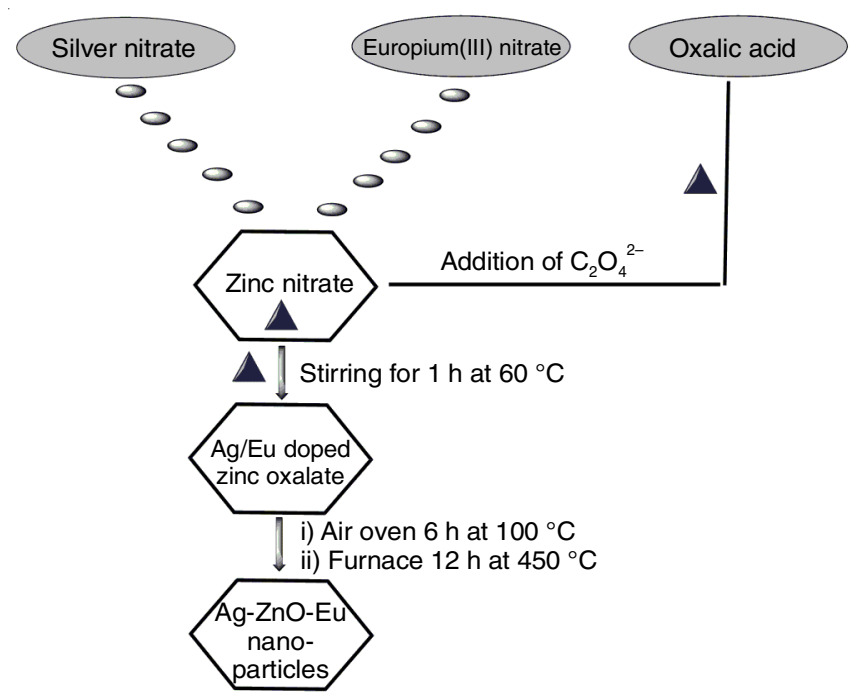

Scheme-I: Schematic preparation of Eu-ZnO-Ag nanoparticles

Analytical methods: $\mathrm{X}$-ray diffraction pattern was obtained using an X'Pert PRO diffractometer outfitted with $\mathrm{Cu}-\mathrm{K}_{\alpha}(\lambda=$ $1.5406 \AA$ ) radiation at $2.2 \mathrm{~kW}$ (max), The morphology of the catalyst analysis by JEOL JSM-6701F scanning electron microscope. Before SEM measurements, equipped with OXFORD, energy dispersive X-ray microanalysis (EDS). The FT-IR spectra of the nano particles were recorded on a Thermo Nicollet6700 , FT-IR instrument in the range $4000-400 \mathrm{~cm}^{-1}(\mathrm{KBr}$ pellet technique). A photo illumination was recorded with a HoribaJobinYvon, SPEX-SF13-11 spectroflourimeter. Optical spectra are recorded in Shimadzu, (UV 2450) double-beam spectrophotometer.

Photodegradation experiments: A photochemical reactor designed $50 \mathrm{~mL}$ capacity with irradiated with LEDs and solar light illuminations. The Eu-ZnO-Ag was magnetically stirred in absence of light illuminations for $30 \mathrm{~min}$ to reach adsorptiondesorption equilibrium between the methylene blue dye and photo-catalyst nanoparticles. At expected time intervals, $3 \mathrm{~mL}$ of the photodegrdation study of decomposed sample was taken out and centrifuged solution to take away the catalyst for further analysis. The similar condition was followed for Solar light degradation of methylene blue dye, the Solar light illuminations intensity almost constant through the experiments day time 11 AM-3 PM (Tamilnadu state, India) [18].

\section{RESULTS AND DISCUSSION}

\section{Characterization of catalyst}

Powder XRD analysis: The XRD patterns of the pure $\mathrm{ZnO}$ and $\mathrm{Ag}-\mathrm{ZnO}$ and $\mathrm{Eu}-\mathrm{ZnO}-\mathrm{Ag}$ nanoparticles., diffraction peaks are found at 31.68 (100), 34.36 (002), 36.18 (101) and 56.56 (110) correspond to wurtzite $\mathrm{ZnO}$ planes structure and so reveals that bare $\mathrm{ZnO}$ has the wurtzite structure. Fig. 1 shows the XRD pattern of $\mathrm{Ag}-\mathrm{ZnO}$ and $\mathrm{Eu}-\mathrm{Ag}-\mathrm{ZnO}$ nanoparticles, in addition to the bare $\mathrm{ZnO}$ peaks there is a no new peak obtained and intensity decrease when influence of depends $(\mathrm{Ag} / \mathrm{Eu})$, so confirms the load the low concentration of $\mathrm{Ag} / \mathrm{Eu}$ ions this could not be detected by XRD $[18,19]$. The crystalline sizes of pure/doped $\mathrm{ZnO}$ nanoparticles and $\mathrm{Eu}-\mathrm{Ag}-\mathrm{ZnO}$ nanoparticles were determined via the Debye-Scherrer equation and are found to be 50 and $36 \mathrm{~nm}$, respectively. The average crystalline size of $\mathrm{Eu}-\mathrm{Ag}-\mathrm{ZnO}$ nanoparticles is lower than of pure $\mathrm{ZnO}$.

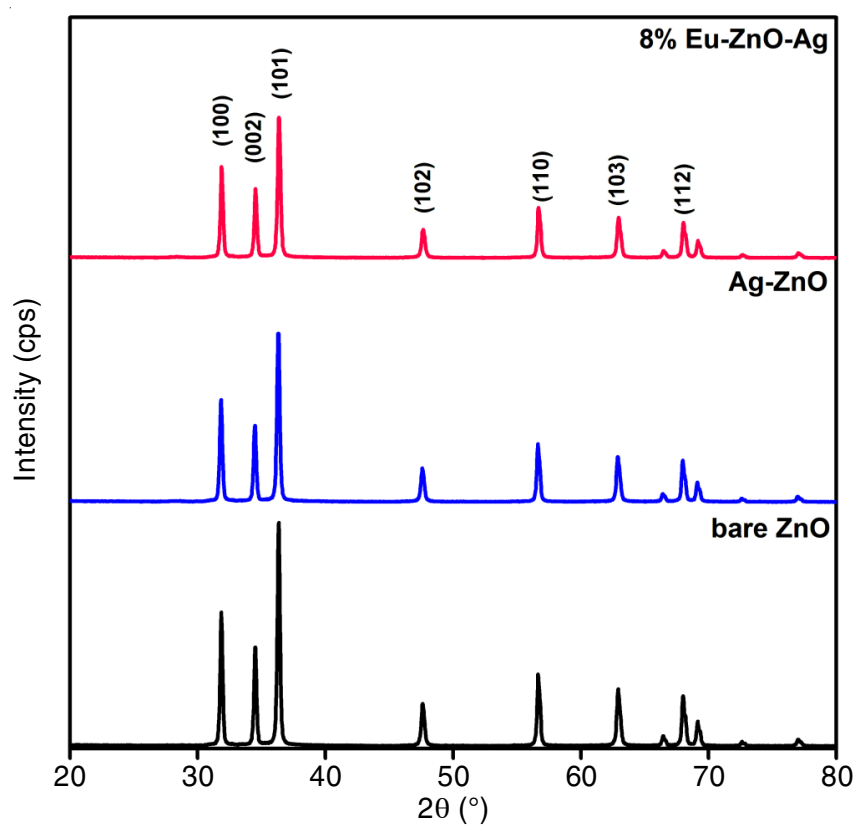

Fig. 1. XRD patterns of $\mathrm{ZnO}, \mathrm{Ag}-\mathrm{ZnO}$ and $\mathrm{Eu}-\mathrm{ZnO}-\mathrm{Ag}$ nanoparticles

SEM analysis: The surface and shape of the photocatalyst are considerable parameters as they influence the catalytic activity. The shape and surface of $\mathrm{Eu}-\mathrm{Ag}-\mathrm{ZnO}$ has been analyzed by SEM images. The SEM analysis images (Fig. 2) at different magnifications on different locations are $\mathrm{Eu}-\mathrm{Ag}-\mathrm{ZnO}$ exhibits "hexagonal and chain like" structure of $\mathrm{ZnO}$ is clearly indicate wurtzite structure of $\mathrm{Eu}-\mathrm{Ag}-\mathrm{ZnO}$ nanoparticles. The 

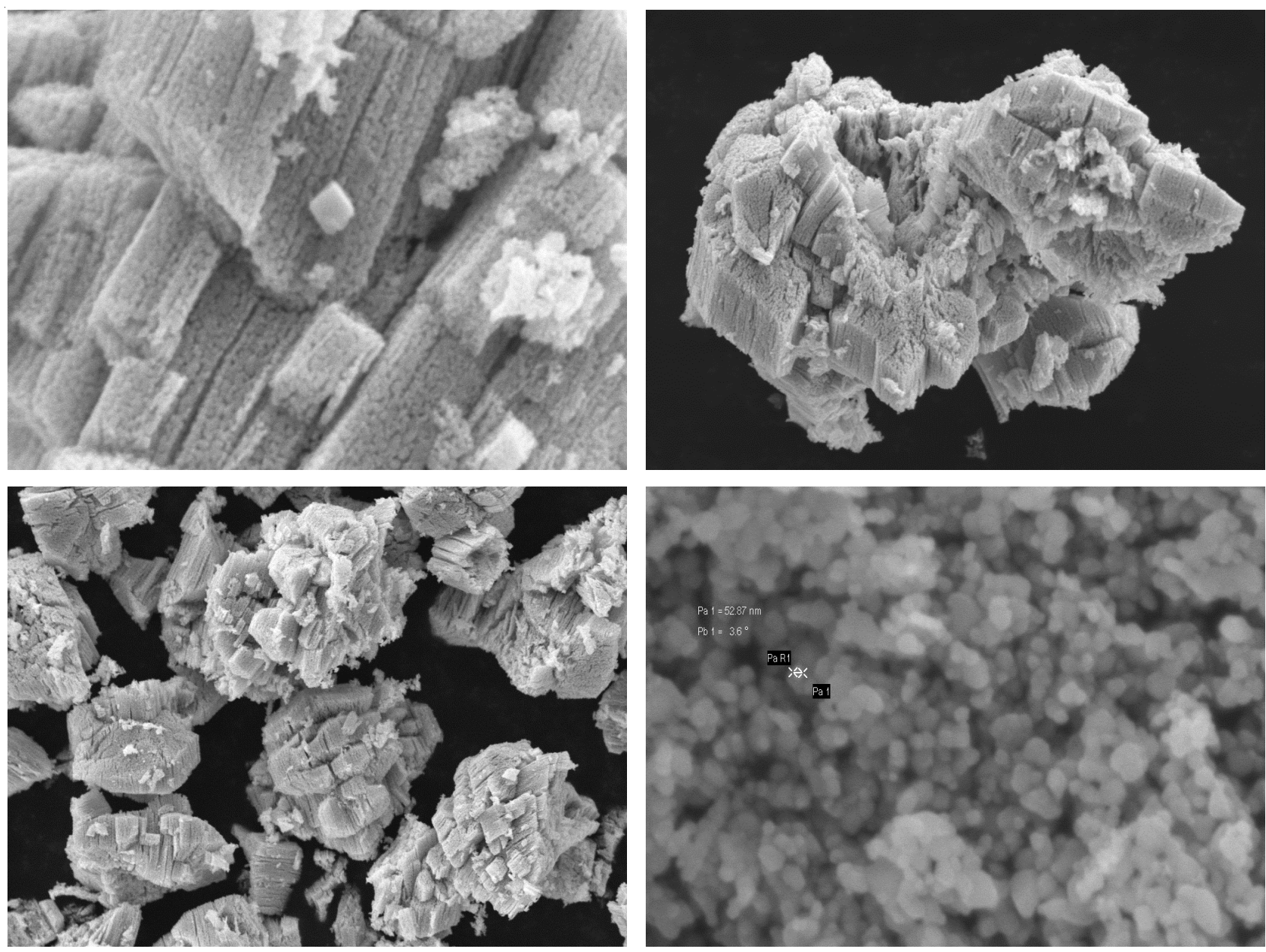

Fig. 2. FE-SEM images at different magnification $(1 \mu \mathrm{m}, 2 \mu \mathrm{m}, 200 \mathrm{~nm})$ of $8 \% \mathrm{Eu}-\mathrm{ZnO}-\mathrm{Ag}$ nanoparticles

Eu particles are highly spread over the surface of photocatalyst, similar morphology also observed in $2 \%$ and $4 \%$ Eu-ZnO$\mathrm{Ag}$ catalyst The EDS of Eu-ZnO-Ag reveals the presence of (Fig. 3) Eu, Ag, Zn and O. The particle sizes of catalyst are in the range of $35-200 \mathrm{~nm}$.

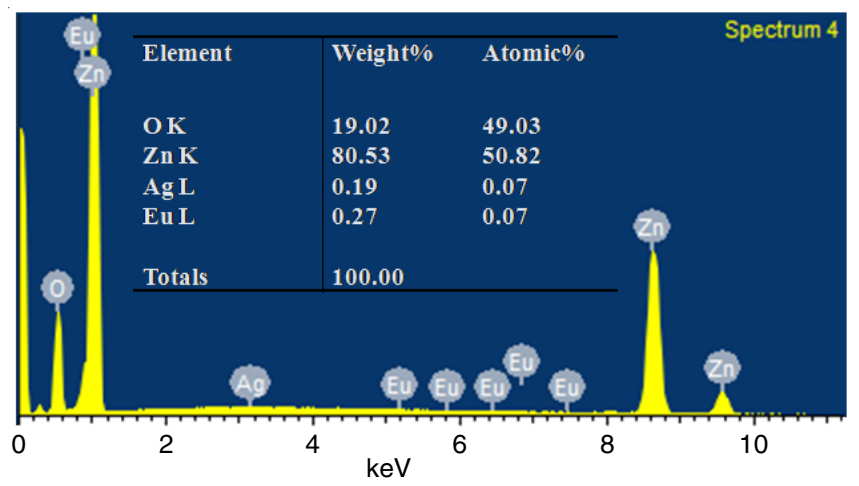

Fig. 3. EDAX images at $8 \% \mathrm{Eu}-\mathrm{ZnO}-\mathrm{Ag}$ nanoparticles

Optical properties of catalyst: A red shift absorbed edge from 360 to $420 \mathrm{~nm}$ appeared for silver and europium doped in $\mathrm{ZnO}$ nanoparticles (Figs. 4 and 5). The red shift in the absorption explains for band gap decreased compare pure $\mathrm{ZnO}$ nanoparticles [20] conformed that presence of $\mathrm{Eu}-\mathrm{ZnO}-\mathrm{Ag}$ bonds. It is commonly consider that the red shift is conforming by the new energy level in the band gap $(3.01 \mathrm{eV})$.

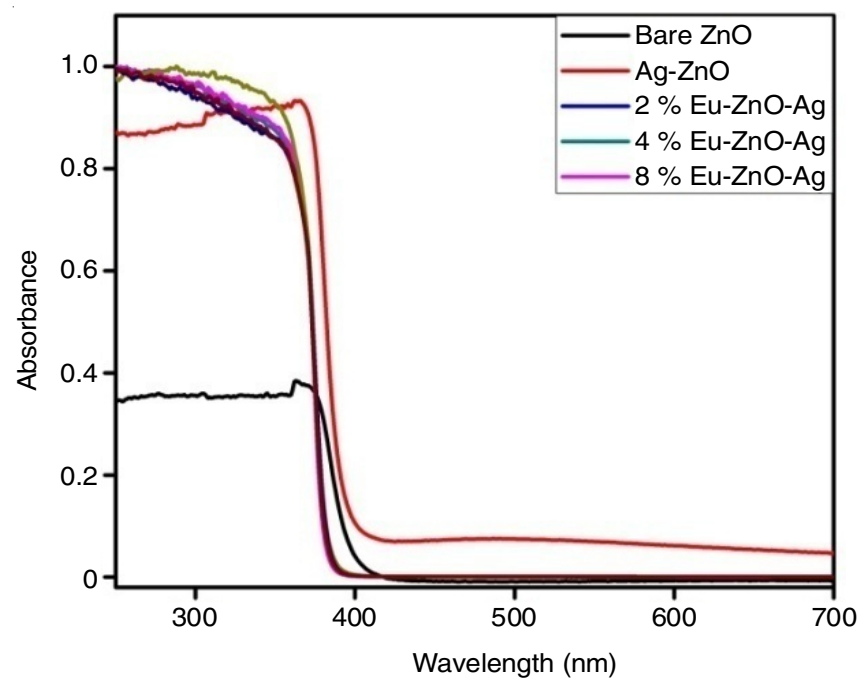

Fig. 4. UV-visible spectra of $\mathrm{ZnO}, \mathrm{Ag}-\mathrm{ZnO}$ and $\mathrm{Eu}-\mathrm{ZnO}-\mathrm{Ag}$ nanoparticles

As a result, $\mathrm{Eu}-\mathrm{ZnO}-\mathrm{Ag}$ has an electron trapping level, which decreases than pure $\mathrm{ZnO}$ nanoparticles and the europium doping enhances the visible light absorption capacity of the doped $\mathrm{ZnO}$ photocatalyst. The DRS spectra of the obtained and the red shift evidently shows that the sharp band gap produced from Eu ion $4 f$ level to $\mathrm{ZnO}$ valence or conduction band there is CT spectra [21]. FTIR spectra explain various functional groups and metal-oxide (MO) bond are analyzed. 


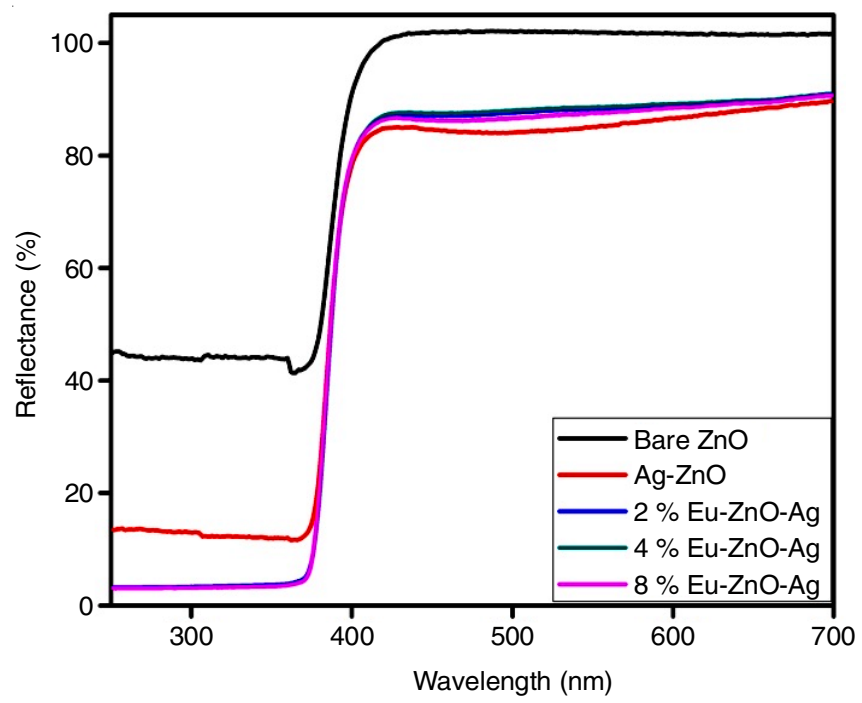

Fig. 5. Diffuse reflectance spectra of $\mathrm{ZnO}, \mathrm{Ag}-\mathrm{ZnO}$ and $\mathrm{Eu}-\mathrm{ZnO}-\mathrm{Ag}$ nanoparticles

In the FTIR spectrum, a important band at about 475 and 425 $\mathrm{cm}^{-1}$ is assigned to the characteristic stretching/bending mode of Ag-O, Eu-O and Zn-O bond. Absorption band at 3425-3325 $\mathrm{cm}^{-1}$ arises due to the stretching mode of O-H group, which reveals the existence of aqueous absorbed by the pure $\mathrm{ZnO}$ and doped $\mathrm{ZnO}$ nanoparticles (Fig. 6).

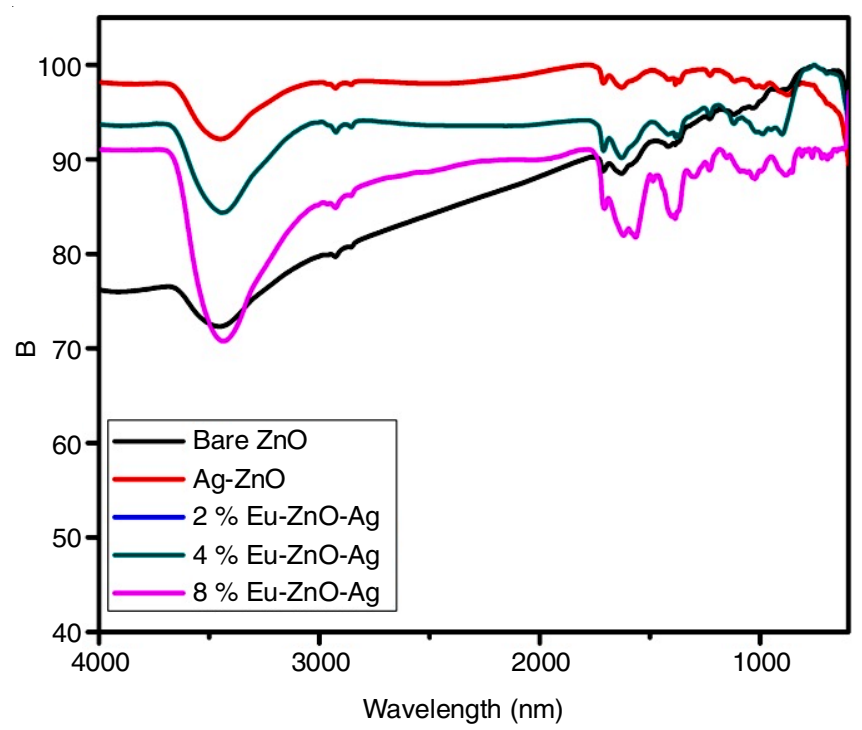

Fig. 6. FT-IR Spectra of $\mathrm{ZnO}, \mathrm{Ag}-\mathrm{ZnO}$ and $\mathrm{Eu}-\mathrm{ZnO}-\mathrm{Ag}$ nanoparticles

Fig. 7 showed the band gap energies by the plot of the modified Kubelka-Munk function, $[\mathrm{F}(\mathrm{R}) \mathrm{E}]^{1 / 2}$ vs. the energy of the absorbed light, we observed the band gap of Eu-ZnO$\mathrm{Ag}$ is $3.01 \mathrm{eV}$. The pure $\mathrm{ZnO}$ nanoparticles showed three emissions bands at 420, 480 and $540 \mathrm{~nm}$ (Fig. 8). The doping of Eu/Ag with $\mathrm{ZnO}$ do not shift any emission of $\mathrm{ZnO}$ but the intensity of emission reduced than pure $\mathrm{ZnO}$ nanoparticles (Fig. 5). This photoluminescence intensity changes due to recombination of electron-hole pairs by dopants ions. This reduces the photoluminescence intensity as a result of the reduction of the rate of electron-hole recombination excellent the electron transfer reactions in dye degradation study [18].

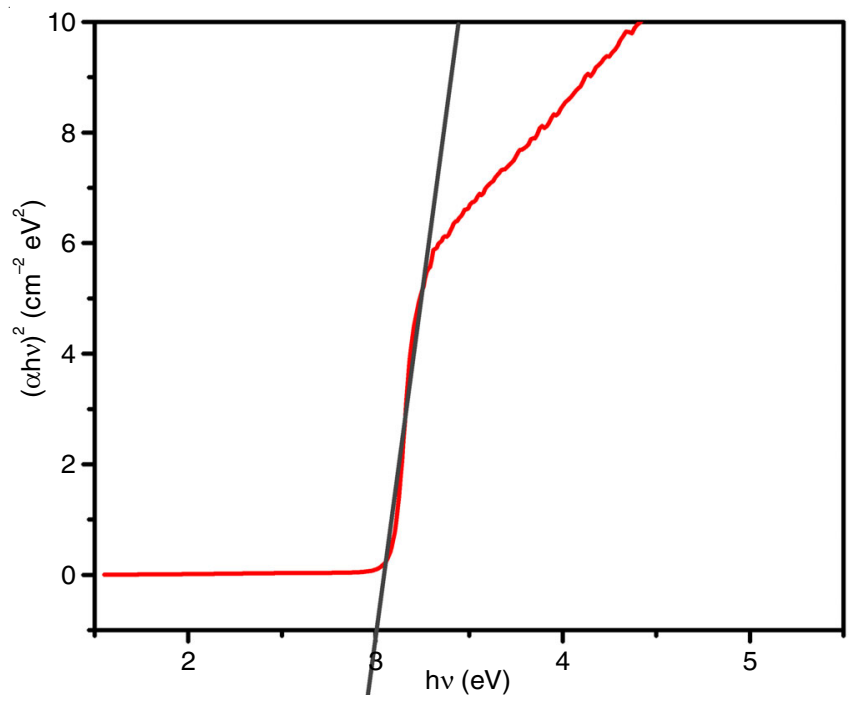

Fig. 7. Plot for (BG) Kubelka-munk function versus energy of the light absorbed of catalyst

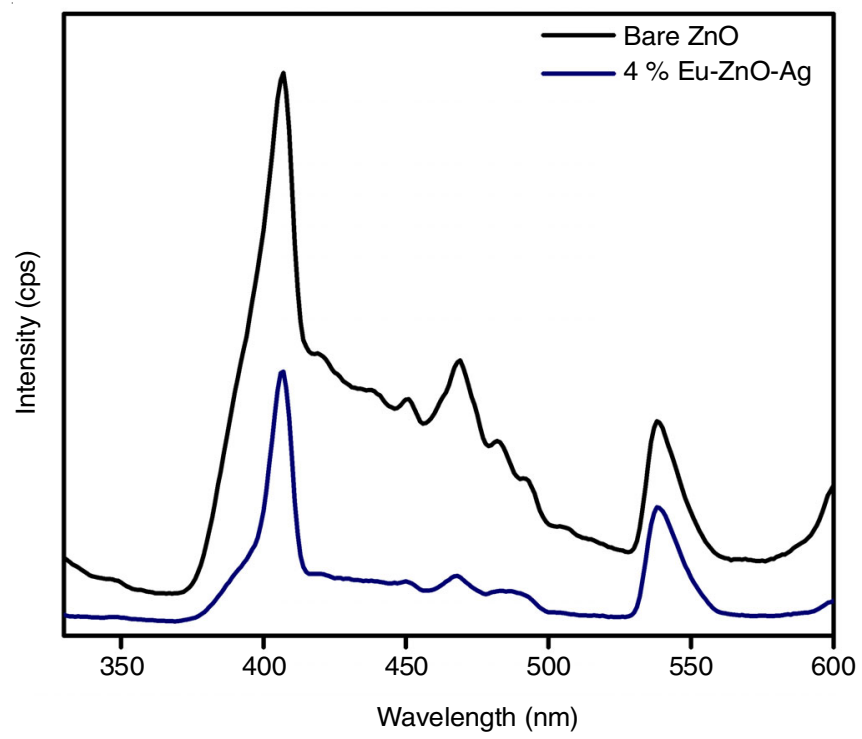

Fig. 8. Photoluminescence spectra of $\mathrm{ZnO}$ and $8 \% \mathrm{Eu}-\mathrm{ZnO}-\mathrm{Ag}$ nanoparticles

\section{Effects of photocatalytic parameters}

Effect of solution pH: The photodegradation mainly focused on adsorption of the dye molecules on the surface of the photocatalyst. The catalyst adsorption of the methylene blue molecules on $\mathrm{pH}$ of the solution depended. The pseudofirst order rate constants for $\mathrm{Eu}-\mathrm{ZnO}-\mathrm{Ag}$ at $\mathrm{pH} /$ rate constant are (3) 0.0269 , (5) 0.0422 , (7) 0.0552, (9) 0.0738 and (11) $0.0482 \mathrm{~min}^{-1}$, respectively after the photo catalyst of adsorption equilibrium $(30 \mathrm{~min})$ in Fig. 9. It is observed that linearly increase (3-9) in $\mathrm{pH}$ from 9 increases the removal efficiency of methylene blue and then decreases. An acidic medium poorer result is obtained due to the suspension of photocatalyst. The efficient of degradation observed basic medium with (pH-9) adsorption of methylene blue molecules on the surface of the catalyst.

Effect of catalyst dosage: Fig. 10 showed photo-degradation pseudo-first order rate constant of methylene blue dye under LEDs light with different catalyst dose amount $1 \mathrm{~g}$ (0.0637), $2 \mathrm{~g}(0.0738), 3 \mathrm{~g}(0.0729), 4 \mathrm{~g}(0.0729)$ and $5 \mathrm{~g}(0.0728$ 


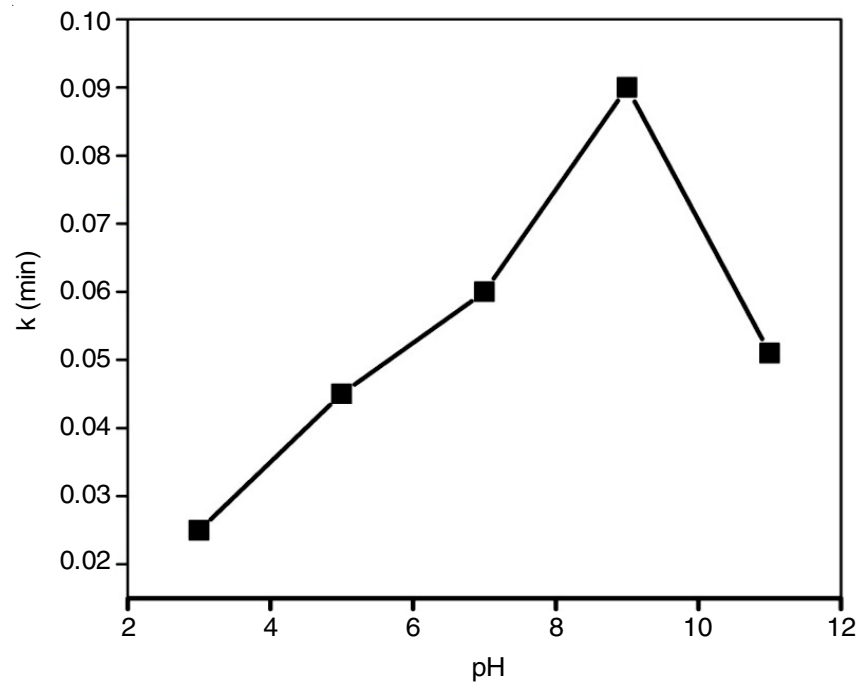

Fig. 9. Effect of solute ion $\mathrm{pH}$; [methylene blue] $=10^{-5} \mathrm{~mL}^{-1}, 8$ wt $\%$ Eu$\mathrm{ZnO}-\mathrm{Ag}$ nanoparticles catalysis suspended $=500 \mathrm{mg} \mathrm{L}^{-1}$, irradiation time $=80 \mathrm{~min}$

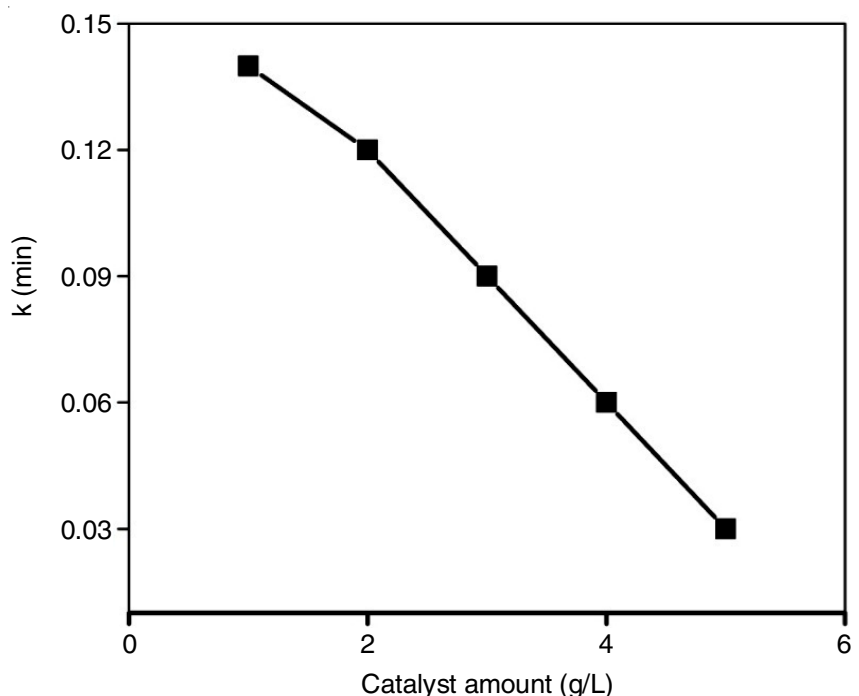

Fig. 10. Effect of catalyst loading, [methylene blue] $=10^{-5} \mathrm{~mol} \mathrm{~L}^{-1}$, catalyst used $=8$ wt $\% \mathrm{Eu}-\mathrm{ZnO}-\mathrm{Ag}$ nanoparticles, $\mathrm{pH}=11$, irradiation time $=80 \mathrm{~min}$

$\min ^{-1}$ ) for nanoparticles. The degradation reaction rate decreases with increasing catalyst dosage amount. The Eu- $\mathrm{ZnO}-\mathrm{Ag}$ nanoparticles surface area of catalyst may influence rate of the reactions. The rate of degradation decreased in methylene blue at higher dosage may be due to light absorption effect by the catalyst.

Effect of initial dye concentration: Fig. 11 showed a range of initial concentrations of methylene blue degradation on $\mathrm{Eu}-\mathrm{ZnO}-\mathrm{Ag}$ was investigated. Influence of dye concentration from $1-5 \times 10^{-4} \mathrm{M}$ photo-degradation from 0.1370 to $0.0262 \mathrm{~min}^{-1}$ at $30 \mathrm{~min}$ the rate constant was decrease linearly. The photodegradation efficiency is low in higher concentration due to the light absorption by catalyst and dye molecules.

Photodegradability of methylene blue with LEDs/Solar illuminations: The photo-catalytic activity of methylene blue with $\mathrm{Eu}-\mathrm{ZnO}-\mathrm{Ag}$ and doped/undoped $\mathrm{ZnO}$ nanoparticles under LEDs illuminations in different time intervals (Fig. 12). Nearly complete degradation was observed in 80 min of methy-

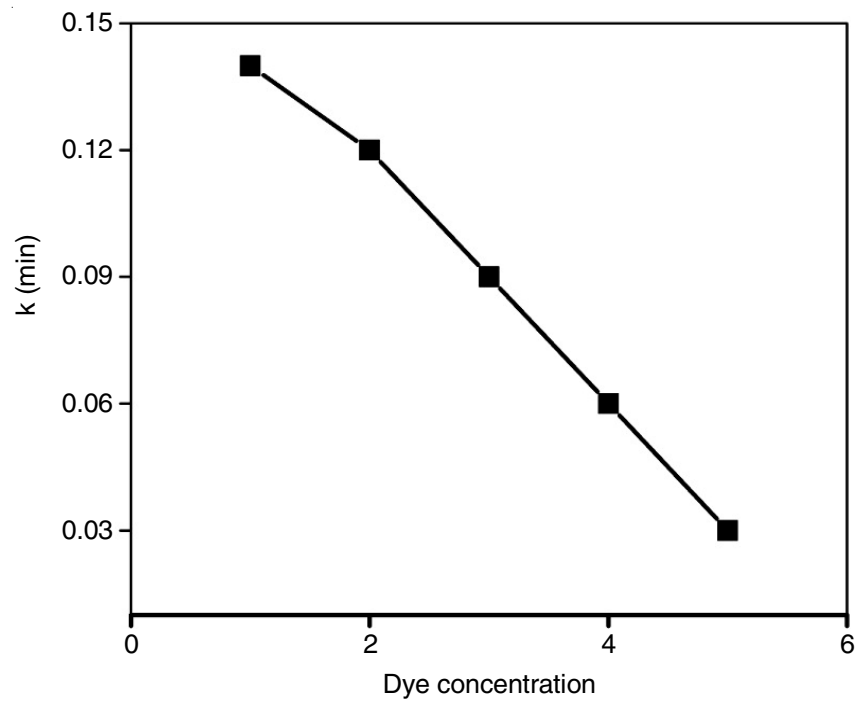

Fig. 11. Effect of initial concentration of methylene blue on irradiation with LED lights in the presence $8 \% \mathrm{Eu}-\mathrm{ZnO}-\mathrm{Ag}$ nanoparticles; $\mathrm{pH}=$ 11 , catalyst suspension $=0.50 \mathrm{~g} \mathrm{~L}^{-1}$ at different initial concentration

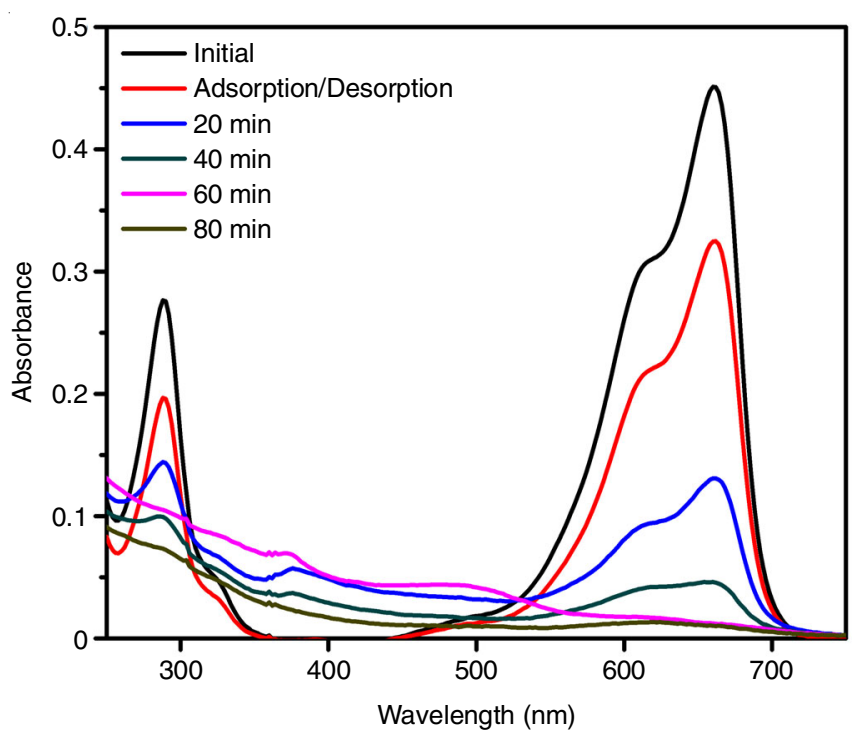

Fig. 12. UV-visible spectra on irradiation of methylene blue with LED light in the presence of $8 \% \mathrm{Eu}-\mathrm{ZnO}-\mathrm{Ag}$ : [methylene blue] $=10^{-5} \mathrm{M}$; $\mathrm{pH}=11$; catalyst suspension $=0.5 \mathrm{~g} \mathrm{~L}^{-1}$; at different time intervals

lene blue molecules with $\mathrm{Eu}-\mathrm{ZnO}-\mathrm{Ag}$ under LEDs light. Photo-degradation $(0.4 \%)$ slight occurred while the reaction was studied in presence of LEDs without any photo-catalyst, The same experiment performed on Eu-ZnO-Ag in absence of LEDs light we absorbed $24 \%$ of dye molecule removed, which may be due to adsorption of the methylene blue by catalyst. From these annotations, We concluded that effective degradation of the methylene blue dye performed by the both LEDs and photocatalyst [18,22,23].

When the photocatalytic activity of $\mathrm{Ag}-\mathrm{ZnO}$, bare $\mathrm{ZnO}$ nanoparticles were used in same conditions 32 and $37 \%$ degradations occurred, compared to others more efficient occurred in $\mathrm{LEDs} / \mathrm{Eu}-\mathrm{ZnO}-\mathrm{Ag}$ nanoparticles degradation of methylene blue dye molecules (Fig. 13). The methylene blue degradation study containing Eu-ZnO-Ag obeys pseudo-first order kinetics. At low initial methylene blue dye concentration, the pseudofirst rate equation by: 


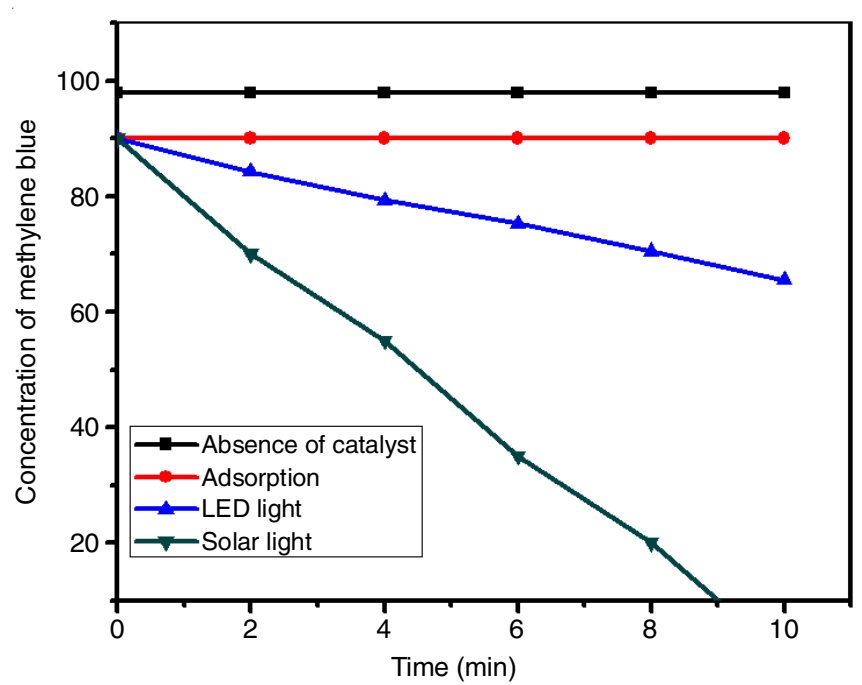

Fig. 13. Comparison of photodegradability of methylene blue between solar and LED lights; dye concentration $=10^{-5} \mathrm{~mol} \mathrm{~L}^{-1}$, catalyst suspension $=0.5 \mathrm{~g}^{1}, \mathrm{pH}=11$ with $\% 8 \mathrm{Eu}-\mathrm{ZnO}-\mathrm{Ag}$ nanoparticles

$$
\mathrm{d}[\mathrm{C}] / \mathrm{dt}=\mathrm{k}_{0}[\mathrm{C}]
$$

where $\mathrm{k}_{0}$ is the pseudo-first order rate constant, $\mathrm{C}$ is methylene blue dye concentration. The surface photocatalyst on the adsorption-desorption equilibrium is reach methylene blue dye molecule at $30 \mathrm{~min}$. After adsorption, the equilibrium dye solution with catalyst is resolute and is taken as the initial dye concentration for chemical kinetic degradation. Further modified of eqn. 2 :

$$
\ln \left(\mathrm{C}_{0} / \mathrm{C}\right)=\mathrm{k}_{0} \mathrm{t}
$$

where $\mathrm{C}_{0}$ is the equilibrium concentration of methylene blue dye and $\mathrm{C}$ is the concentration at time $\mathrm{t}$. The absorption spectra of methylene blue dye $\left(5 \times 10^{-4} \mathrm{M}\right)$ solution at different irradiation periods in Fig. 14. The UV-visible spectra in irradiation and the intensity at $\lambda_{\max } 660 \mathrm{~nm}$ decreases regularly during the photo-degradation. This reveals that the intermediates $\lambda_{\max }$ $380 \mathrm{~nm}$ peaks absorb after $20 \mathrm{~min}$ degradation due to some aromatic amine compounds present in solution. In presence of solar light $28 \%$ methylene blue dye absorption/desorption occurred in the experiment perform with $8 \% \mathrm{Eu}-\mathrm{ZnO}-\mathrm{Ag}$ (without solar light). A very poor (3\%) degradation absorbed when the same experiment in methylene blue with solar light (without catalyst). More efficient phtodegradation of methylene blue dye depending on solar light and calalysts. The photocatalysts bare $\mathrm{ZnO}, \mathrm{Ag}-\mathrm{ZnO}, \mathrm{Eu}-\mathrm{ZnO}-\mathrm{Ag}$ nanoparticles, were used under the same conditions, 60, 65.9, 85.3, 91.4, $100 \%$ degradations occur (Fig. 15), respectively. The $8 \%$ $\mathrm{Eu}-\mathrm{ZnO}-\mathrm{Ag}$ catalyst is excellent efficient than compared to related catalyst for photo-degradation of methylene blue (Fig. 15). It is clear that the solar degradation is much better than LED degradation.

Stability and reusability of photo-catalyst: The excellent performance of heterogeneous photo-catalysts used for many reactions is its reusability. The reusability of $\mathrm{Eu}-\mathrm{ZnO}-\mathrm{Ag}$ nanoparticles verified by four consecutive cycles for the photodegradation of methylene blue dye (Fig. 14).

Mechanism of degradation: The photocatalyst study degradation of methylene blue dye illuminate by LEDs/solar

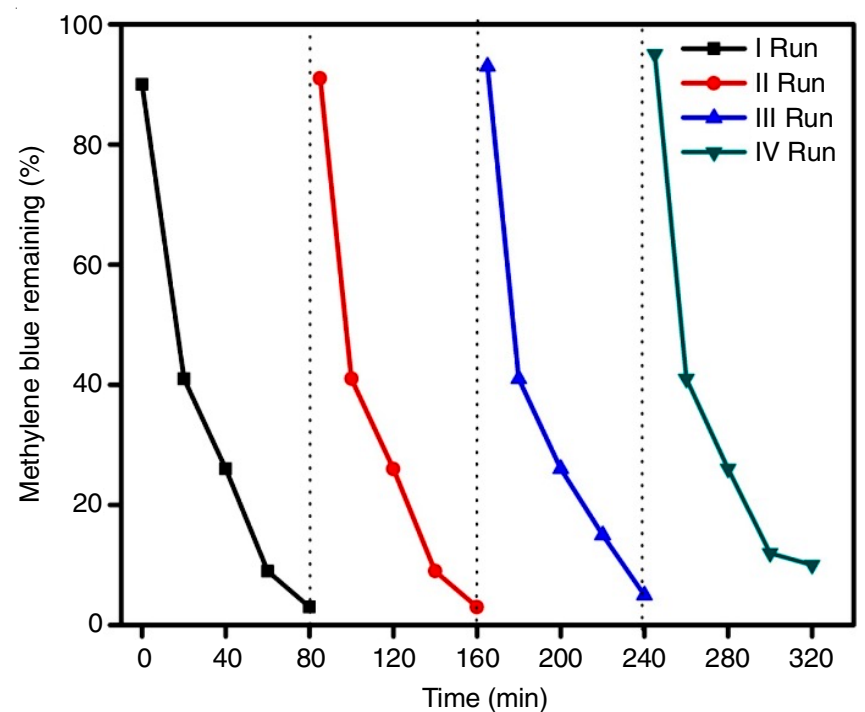

Fig. 14. Catalyst reusability, [methylene blue] dye concentration $=10^{-5} \mathrm{~mol}$ $\mathrm{L}^{-1}$ catalyst suspension $(8 \% \mathrm{Eu}-\mathrm{ZnO}-\mathrm{Ag}$ nanoparticles $)=0.5 \mathrm{~g} \mathrm{~L}^{-1}$, $\mathrm{pH}=11$ LED and solar lights

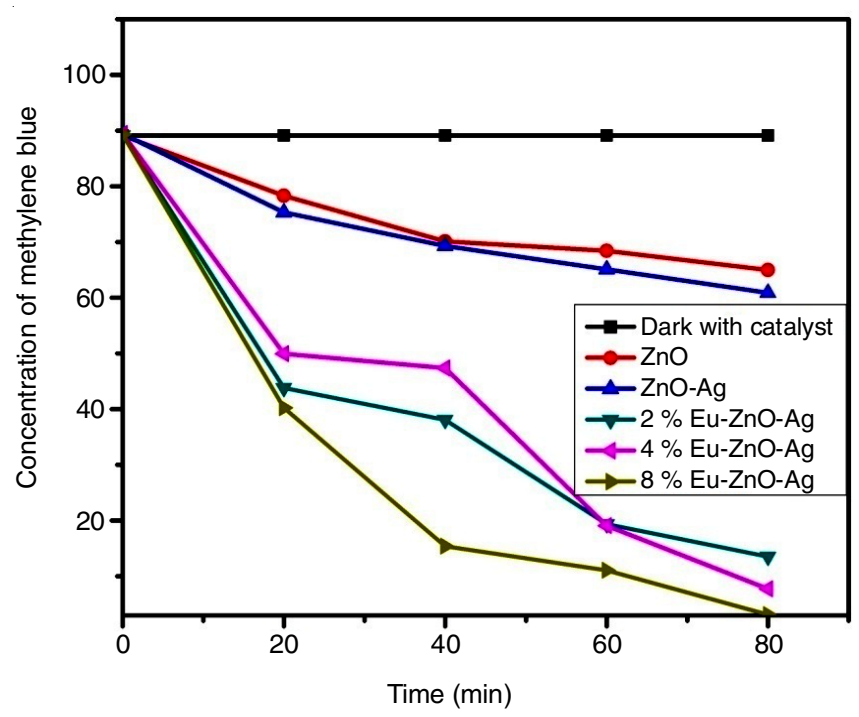

Fig. 15. Photodegradability of methylene blue; dye concentration $=10^{-5}$ mol L ${ }^{-1}$, catalyst suspension $=0.5 \mathrm{~g} \mathrm{~L}^{-1}, \mathrm{pH}=11$ with $\mathrm{ZnO}$ bare and $\mathrm{Eu}-\mathrm{ZnO}-\mathrm{Ag}$ nanoparticles

irradiation [22,23], a valence band electron goes to the conduction band leaving a hole in the valance band, regularly. These electron-hole pairs explain the activity of photocatalyst. Though, the presence of 'Eu' and 'Ag' traps the electron from the conduction band of $\mathrm{ZnO}$ concurrently, which suppress the electronhole generated. It is well-known that 'Ag' can trap the electrons from the conduction band of $\mathrm{ZnO}$ during the presence of irradiation source in the photocatalytic degradation of methylene blue dye molecule. This excellent the photocatalytic behaviour of $\mathrm{Eu}-\mathrm{ZnO}-\mathrm{Ag}$ due to a electron-trapped between $\mathrm{Ag}$ and $\mathrm{Eu}$ in $\mathrm{ZnO}$ nanoparticles. Fig. 8 showed that the photocatalytic activity of Eu-ZnO-Ag nanoparticles is higher than that of pure and monodoped $\mathrm{ZnO}$ nanoparticles.

The mechanism of photocatalyst suggest itself electron trap from the photo-generated in oxygen adsorbed on the surface of photocatalyst and the electron shift to $\mathrm{O}_{2}$ molecule its connecting catalyst on rate-determining step. on the other hand, $\mathrm{Eu}^{3+}$ 
easily traps the photo-excited electronin the system of Eudoped catalyst, because $\mathrm{Eu}^{2+}$ ion, act as Lewis acid, it appears that is superior to the oxygen molecule $\left(\mathrm{O}_{2}\right)$ in its ability of trapping electrons $[13,14,18]$. The electrons trapped in $\mathrm{Eu}^{2+}$ sites are consequently transferred due to the $\mathrm{O}_{2}$ adsorbed by an oxidation process, so the band gap and holes is reduced (Scheme-II).

$$
\begin{gathered}
* \text { Dye }+ \text { Eu-ZnO-Ag } \longrightarrow \text { Dye }+\mathrm{Eu}-\mathrm{ZnO}-\mathrm{Ag}+\mathrm{e}_{\mathrm{cb}^{-}} \\
\mathrm{e}_{\mathrm{cb}^{-}}+\mathrm{O}_{2} \longrightarrow \mathrm{O}_{2}^{--} \\
\text {Dye }^{\cdot-}+\mathrm{O}_{2} / \mathrm{O}_{2}^{-} \longrightarrow \text { Degradation products }
\end{gathered}
$$

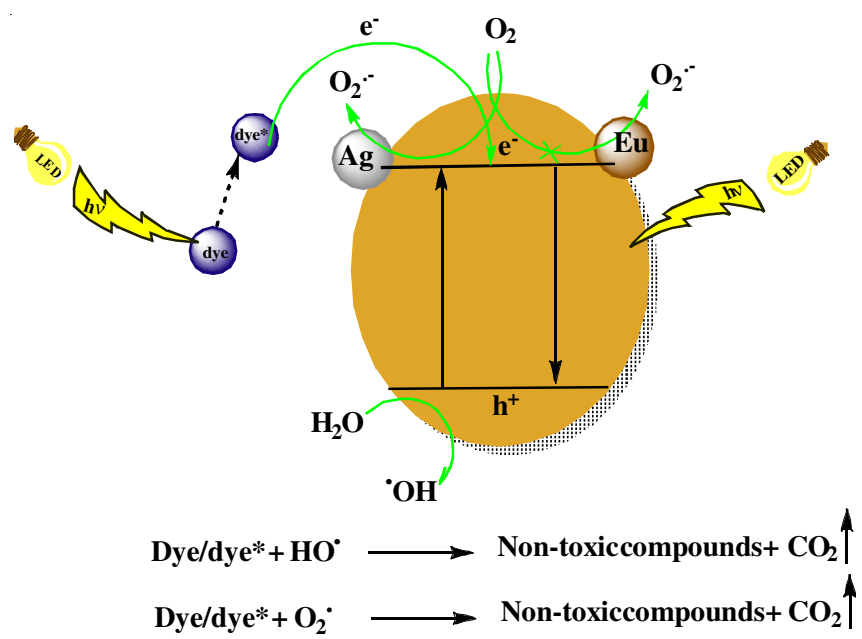

Scheme-II: Enhanced photocatalytic activity mechanism of $\mathrm{Eu}-\mathrm{ZnO}-\mathrm{Ag}$ nanoparticles in present of LED/solar lights illuminations

The activity of Eu $4 f$ level in Eu-ZnO-Ag acting an important role in the interfacial electron transfer and electronhole inhibition generation. The optical spectra showed that doping of $\mathrm{Ag}$ and Eu excellent the visible light absorption of catalyst and engender more electron-hole pairs in LEDs/solar light illumination, which enhanced to increase the photocatalytic activity of $\mathrm{Eu}-\mathrm{ZnO}-\mathrm{Ag}$ nanoparticles. Since $\mathrm{Eu}^{2+}$ traps the electron straight forwardly, its act as a scavenger of electrons. $\mathrm{So} \mathrm{Eu}^{2+}$ and $\mathrm{Eu}^{3+}$ accessible in $\mathrm{Eu}-\mathrm{ZnO}-\mathrm{Ag}$ influence the photoreactivity by shifting the electron-hole pair formed. Moreover, the trapping nature of $\mathrm{Ag}$ and $\mathrm{Eu}^{2+} / \mathrm{Eu}^{3+}$ sites are consequently transferred to the adjacent adsorbed $\mathrm{O}_{2}$ to produce a great number of superoxide radical anions. The well reactive hydroxyl radicals and superoxide radical anion show the way to the methylene blue dye degradation. The excellent creation of $\mathrm{O}_{2}{ }^{-}$and ${ }^{-} \mathrm{OH}$ by Eu and Ag increases the photocatalytic activity of Eu-ZnO-Ag nanoparticles.

\section{Conclusion}

The successfully synthesized (Eu-ZnO-Ag) nanoparticles by precipitation-decomposition method. The characterization of photo-catalyst by XRD, FE-SEM images, EDS, optical measurements. The absorption of $\mathrm{ZnO}$ to doped $\mathrm{ZnO}$ nanoparticles are swing visible region due to dopants $(\mathrm{Ag} / \mathrm{Eu})$. Eu- $\mathrm{ZnO}-\mathrm{Ag}$ photocatalyst shows lower reflectance (high absorption) in the visible region than pure $\mathrm{ZnO}$ and shifting of the absorption edge to moved visible region. The photoluminescence spectra explained the self-consciousness of photo electron-hole pairs by loading dopants (Eu/Ag) on $\mathrm{ZnO}$ nanoparticles. The dopants are $\mathrm{Eu}^{2+}$ and 'Ag' trap the photo-excited electrons in solution, so decreasing rate of the electron-hole pairs in catalyst. Excellent photodegradation efficient Eu-ZnO-Ag nanoparticles comparted to commercial $\mathrm{ZnO}$, bare $\mathrm{ZnO}, \mathrm{Eu}-\mathrm{ZnO}, \mathrm{Ag}-\mathrm{ZnO}$. The optimum catalyst dosage and $\mathrm{pH}$ of solution for completely removal of methylene blue dye. A mechanism of excellent photocatalytic activity of Eu-ZnO-Ag nanoparticles showed electron trapping by dopants. The Eu-ZnO-Ag nanoparticles playing reusable photocatalyst.

\section{CONFLICT OF INTEREST}

The authors declare that there is no conflict of interests regarding the publication of this article.

\section{REFERENCES}

1. U.I. Gaya and A.H. Abdullah, J. Photochem. Photobiol. Photochem. Rev., 9, 1 (2008); https://doi.org/10.1016/j.jphotochemrev.2007.12.003.

2. K. Nakata and A. Fujishima, J. Photochem. Photobiol. Photochem. Rev., 13, 169 (2012); https://doi.org/10.1016/i.jphotochemrev.2012.06.001.

3. A. Fujishima and K. Honda, Nature, 238, 37 (1972); https://doi.org/10.1038/238037a0.

4. I. Muthuvel and M. Swaminathan, Catal. Commun., 8, 981 (2007); https://doi.org/10.1016/j.catcom.2006.10.015.

5. I. Muthuvel, B. Krishnakumar and M. Swaminathan, J. Environ. Sci., 24, 529 (2012);

https://doi.org/10.1016/S1001-0742(11)60754-7.

6. H. Huang, D.Y.C. Leung, P.C.W. Kwong, J. Xiong and L. Zhang, Catal. Today, 201, 189 (2013);

https://doi.org/10.1016/j.cattod.2012.06.022.

7. M. Lazar, S. Varghese and S. Nair, Catalysts, 2, 572 (2012); https://doi.org/10.3390/catal2040572.

8. M.V. Enoch, R. Rajamohan and M. Swaminathan, Spectrochim. Acta A Mol. Biomol. Spectrosc., 77, 473 (2010);

https://doi.org/10.1016/j.saa.2010.06.021

9. S. Singhal, J. Kaur, T. Namgyal and R. Sharma, Physica B, 407, 1223 (2012); https://doi.org/10.1016/i.physb.2012.01.103.

10. R. Chauhan, A. Kumar and R.P. Chaudhary, J. Sol-Gel Sci. Technol., 63, 546 (2012); https://doi.org/10.1007/s10971-012-2818-3.

11. D. Daniel and I.G.R. Gutz, Electrochem. Commun., 9, 522 (2007) https://doi.org/10.1016/j.elecom.2006.10.014.

12. S. Han, Y. Tang, H. Guo, S. Qin and J. Wu, Nanoscale Res. Lett., 11, 273 (2016); https://doi.org/10.1186/s11671-016-1497-3.

13. A.R. Khataee, A. Karimi, R.D.C. Soltani, M. Safarpour, Y. Hanifehpour and S.W. Joo, Appl. Catal. A Gen., 488, 160 (2014); https://doi.org/10.1016/i.apcata.2014.09.039.

14. A. Phuruangrat, O. Yayapao, T. Thongtem and S. Thongtem, J. Nanomater, 2014, Article ID 367529 (2014); https://doi.org/10.1155/2014/367529.

15. S. Anandan, Y. Ikuma and V. Murugesan, Int. J. Photoenergy, 2012, Article ID 921412 (2012); https://doi.org/10.1155/2012/921412.

16. R. Kumar, A. Umar, G. Kumar, M.S. Akhtar, Y. Wang and S.H. Kim, Ceram. Int., 41, 7773 (2015);

https://doi.org/10.1016/j.ceramint.2015.02.110.

17. C. Jayachandraiah, K.S. Kumar, G. Krishnaiah and N.M. Rao, J. Alloys Compd., 623, 248 (2015); https://doi.org/10.1016/j.jallcom.2014.10.067.

18. Y.J. Jose, M. Manjunathan and S.J. Selvaraj, J. Nanostruct. Chem., 7, 259 (2017);

https://doi.org/10.1007/s40097-017-0236-3.

19. N. Rajendiran and M. Swaminathan, Spectrochim. Acta A Mol. Biomol. Spectrosc., 52, 1785 (1996); https://doi.org/10.1016/S0584-8539(96)01704-7.

20. N.V. Kaneva, D.T. Dimitrov and C.D. Dushkin, Appl. Surf. Sci., 257, 8113 (2011); https://doi.org/10.1016/j.apsusc.2011.04.119.

21. S. Velanganni, S. Pravinraj, P. Immanuel and R. Thiruneelakandan, Physica B, 534, 56 (2018); https://doi.org/10.1016/j.physb.2018.01.027.

22. B. Subash, B. Krishnakumar, R. Velmurugan, M. Swaminathan and M. Shanthi, Catal. Sci. Technol., 2, 2319 (2012); https://doi.org/10.1039/c2cy20254a.

23. W.-K. Jo and R.J. Tayade, Chin. J. Catal., 35, 1781 (2014); https://doi.org/10.1016/S1872-2067(14)60205-9. 